\title{
Roadmap Document for Pacific Northwest National Laboratory Contribution to the Open Modeling Framework
}

JC Fuller JL Hammerstrom

AR Fisher ML Hauer

S Ciraci KP Schneider

May 2013 



\title{
DISCLAIMER
}

This report was prepared as an account of work sponsored by an agency of the United States Government. Neither the United States Government nor any agency thereof, nor Battelle Memorial Institute, nor any of their employees, makes any warranty, express or implied, or assumes any legal liability or responsibility for the accuracy, completeness, or usefulness of any information, apparatus, product, or process disclosed, or represents that its use would not infringe privately owned rights. Reference herein to any specific commercial product, process, or service by trade name, trademark, manufacturer, or otherwise does not necessarily constitute or imply its endorsement, recommendation, or favoring by the United States Government or any agency thereof, or Battelle Memorial Institute. The views and opinions of authors expressed herein do not necessarily state or reflect those of the United States Government or any agency thereof.

\author{
PACIFIC NORTHWEST NATIONAL LABORATORY \\ operated by \\ BATTELLE \\ for the \\ UNITED STATES DEPARTMENT OF ENERGY \\ under Contract DE-AC05-76RL01830
}

Printed in the United States of America

Available to DOE and DOE contractors from the Office of Scientific and Technical Information,

P.O. Box 62, Oak Ridge, TN 37831-0062; ph: (865) 576-8401 fax: (865)

576-5728 email: reports@adonis.osti.gov

Available to the public from the National Technical Information Service,

U.S. Department of Commerce, 5285 Port Royal Rd., Springfield, VA 22161

ph: (800) 553-6847 fax: (703) 605-6900

email: orders@ntis.fedworld.gov online ordering: http://www.ntis.gov/ordering.htm

This document was printed on recycled paper. 


\title{
Roadmap Document for Pacific Northwest National Laboratory Contribution to the Open Modeling Framework
}

\author{
JC Fuller JL Hammerstrom \\ AR Fisher ML Hauer \\ S Ciraci KP Schneider
}

May 2013

Prepared for

the U.S. Department of Energy

under Contract DE-AC05-76RL01830

Pacific Northwest National Laboratory

Richland, Washington 99354 


\section{Table of Contents}

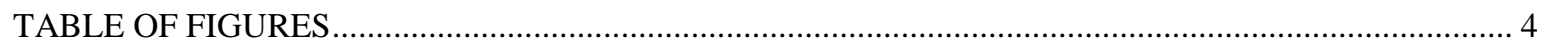

1 INTRODUCTION

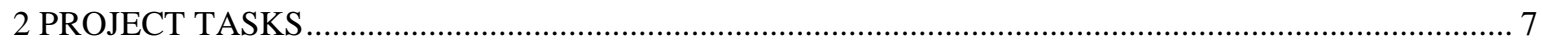

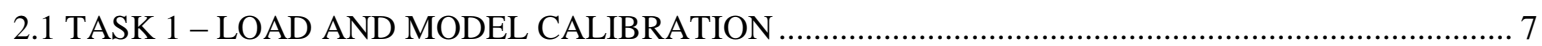

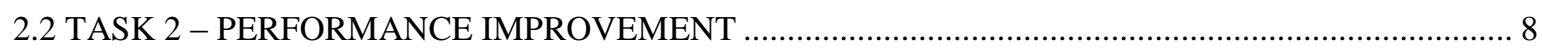

2.3 TASK 3 - DEVELOPMENT OF NEW CAPABILITIES ............................................................... 9

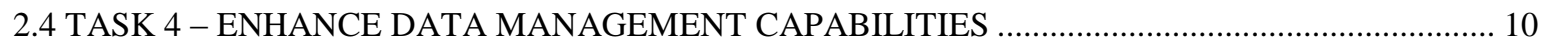

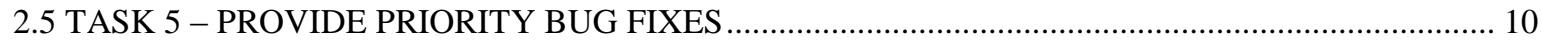

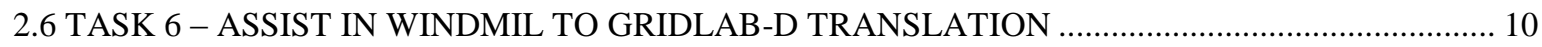

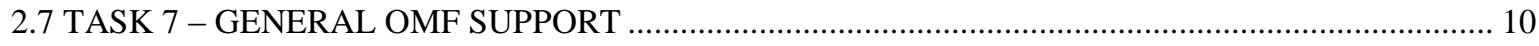

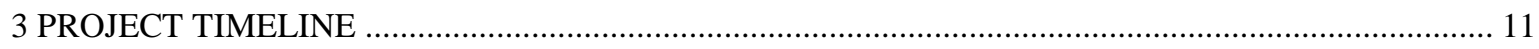

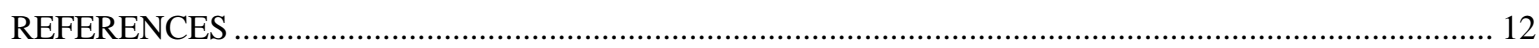




\section{Table of Figures}

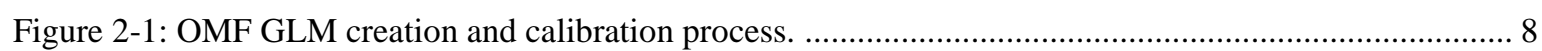

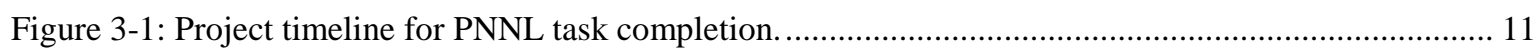




\section{Introduction}

GridLAB-D ${ }^{\mathrm{TM}}$ is a powerful simulation engine, designed to examine all aspects of a distribution system - power components, end use loads, building characteristics, control systems and market structures - in a single environment, so that simulation and analysis properly account for the interactions between these coupled systems [1]. The fusion of these domains allows for a number of emerging technologies to be examined in a more complete manner [2]. GridLAB-D began as an internal research project at Pacific Northwest National Laboratory (PNNL) and was later fully supported and funded by the Department of Energy Office of Electric Delivery and Energy Reliability. The end goal has always been to support the design and operation of the nation's electric infrastructure. By developing new analysis techniques, in an open-source environment, and by sharing the results with academia and industry, measureable impacts have been shown [3][4].

The Cooperative Research Network (CRN) of the National Rural Electric Cooperative Association (NRECA) has identified GridLAB-D as a tool that would provide significant benefit to its member utilities [5]. However, they have also noted that the complexity of the tool would be a significant barrier for adoption. As can often happen in complex simulation environments, as the available capabilities and flexibility increases, the usability of the software decreases except for a few "power" users; this is not unique to GridLAB-D. While GridLAB-D has expanded to a considerable user base, with a few notable exceptions (e.g., American Electric Power) most users are focused on research and development. As a result, NRECA/CRN has proposed an Open Modeling Framework (OMF) designed to make the capabilities of GridLAB$\mathrm{D}$, and other advanced grid tools, available via a web interface [6]. This will allow utility users to access many of the capabilities of GridLAB-D, with little to no knowledge of the tool itself. Other components will be layered over the simulation engines to provide the user with business support functions, allowing full business case scenarios to be created from the technical data generated within the simulations. An extract from the OMF plan is as follows:

"The technology of the electric grid is changing quickly in many ways it would be pedantic to enumerate. From a utility perspective, the challenge in gaining value from the emerging and morphing technology rests on understanding its physical performance in actual operation and translating the physical performance into monetary value relative to cost. Though simply stated, this task can be extraordinarily difficult because the technology is changing and, to some degree, unproven and because value depends on the way the technology is deployed and used. The challenge of assessing the costs and benefits of new technology investments is one of the fundamental challenges to the deployment of the smart grid. The experience of the stimulus grants will provide essential information and demonstration, but even when the technical uncertainty is reduced, modeling will remain necessary to address the unique aspects of individual utilities. 
We believe that development of a consistent modeling framework and tools will provide an invaluable tool to the co-ops and other utilities and accelerate the adoption of new technology. CRN has undertaken development of what we have termed the Open Modeling Framework to address these needs. In the first step of the OMF development, we determined that meaningful analysis requires a highresolution grid simulation capability as part of the modeling framework. After extensive review of the available approaches to this modeling we concluded that GridLAB-D provides the most robust and extensible platform to build around."

This approach has a number of benefits and advantages. It expands upon the open-source nature of GridLAB-D, allowing users from across industry to access the potential modeling and business case capabilities. This is an important national benefit, as it allows users to share their results in a collaborative manner and build a collective database of technology benefits and impacts. This will encourage the deployment of beneficial technologies targeted towards distribution systems that can fully benefit from the additions, while eliminating the deployment of unwarranted technologies. Utilities may eventually require that vendors create (proprietary) add-ons to the OMF, so that new technologies may be fully evaluated before field deployment. 


\section{Project Tasks}

Because of the open availability and potential national benefit of the OMF, PNNL has been tasked with supporting NRECA/CRN's development of the tool, with a focus on incorporating GridLAB-D within the OMF structure and expanding GridLAB-D capabilities to support OMF functions. The GridLAB-D enhancements will be provided first to the OMF developers, but will also be delivered to the wider GridLAB-D community after validation via the community repository [7]. This report is intended to provide a roadmap for the intended enhancements to be delivered by PNNL. Seven tasks were identified in cooperation with NRECA/CRN - each is briefly discussed, including potential outcomes and deadlines.

\subsection{Task 1 - Load and Model Calibration}

NRECA/CRN, among a number of other utility and consultant users, have expressed a desire to use GridLAB-D for planning and investment in new grid technologies. However, the translation from standard or commercial planning models and current industry tools is a difficult and tedious task requiring large amounts of information. Additionally, to convert these models to time series, object-oriented simulations (as are used within GridLAB-D) that are representative of the actual behavior of the system, requires information that is not typically captured by standard models or even collected within the utility. Even after all of the available information is collected and processed, there is often a large number of unknowns (i.e., appliance usage patterns, thermostat setpoints, building construction quality, etc.).

Over time, PNNL staff have developed a manual, human-in-the-loop calibration process to create annual simulations that can be matched against substation or feeder circuit power measurements [8]-[11]. However, this manual process involves a fair amount of background knowledge and certainly bars large-scale usage by utilities and consultants. PNNL will investigate automation of this process, creating a methodology for users to use standard planning models incorporated with time series substation data, and calibrate the GridLAB-D model to create representative annual simulations of the feeder load behavior.

The first step in this process will be to convert current Matlab® scripts for creating calibrated model files into Python, the base language of the OMF. Converting to Python also has the added benefits of (1) re-factoring old code that has been built up over time to make it more efficient and robust and (2) giving the community a truly openly available script (Matlab requires a license, while Python is free to use).

The second step will be to create an automated calibration tool to wrap around the feeder calibration script. It will need to collect limited data from the users (such things as City/State, air conditioner penetration, etc.), pull information from available databases (weather stations, default population statistics, etc.), and create a series of GridLAB-D model files (GLMs) for evaluation. Iteratively, the script will need to narrow in on the unknown parameters to produce a "best fit" between the GLM and the available data for comparison. The current implementation will be reminiscent of a Particle Swarm Optimization (PSO) technique, but will be modified as 
needed. Figure 2-1 describes the overall process to be used in the OMF, where the red coloration describes PNNL's contribution to this formulation.

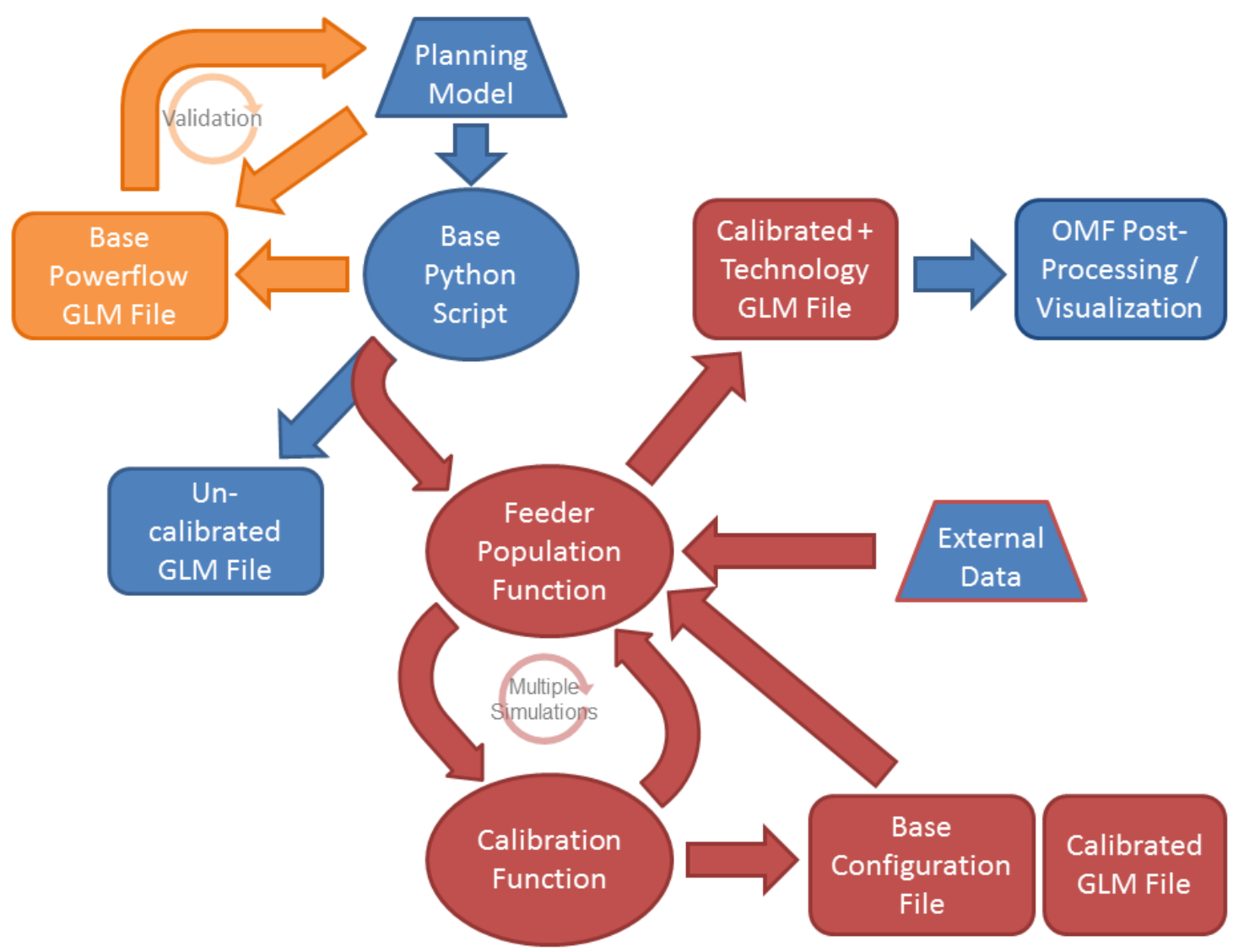

Figure 2-1: OMF GLM creation and calibration process. Blue represents NRECA/CRN or other contributions, red indicates PNNL contributions, and orange represents completed functionality.

\subsection{Task 2 - Performance Improvement}

Because of the complexity of the GridLAB-D simulation environment, simulation runtime can be a limitation to its usability in certain applications. This is especially true in online applications where near instantaneous presentation of the data is expected by users. While it is not expected that GridLAB-D will achieve near instantaneous solution speeds, as the complexity of the problem simulated on an annual basis precludes this, minimizing the solution time is important. In this task, PNNL will focus on improved runtime for GridLAB-D simulations, in terms of both single instance processes and multiple core processes. Due to the high performance nature of this task, and the desire for use in both a production and research environment, efforts will focused on a generic 64-bit Linux platform. 
The power flow simulator, due to its need to solve a linear matrix equation, as is common with most power flow solvers, and its connections to other modules is currently a bottleneck to simulation speed and reduces the effectiveness of parallelization of the simulation. Methods of decoupling the modules / classes over limited time frames will be explored. Parallelization of some of the internal processes within the power flow solver, i.e., list sorts or other 'for' loops, will be investigated for internal speed up. Currently, the internal solver most often used requires a two-pass system; this will be reduced to a single pass system.

Finally, general code 'clean-up' will be performed to better allocate memory, reduce repeated and unnecessary updates, and more efficiently pass information amongst objects. This is part of a larger application programming interface (API) overhaul, but will be focused on elements expected to increase performance rather than accessibility.

The speed improvements will be benchmarked by comparing to GridLAB-D v2.3, released to the public in FY13.

\subsection{Task 3 - Development of New Capabilities}

One of the powerful aspects of GridLAB-D is the exploratory nature of the simulations, allowing users to explore the effects on a distribution network of different control setpoints, various control schemes, climatological variances, energy efficiency programs, comparison of difference technologies, and more. However, this requires a large number of models with only small variances in input parameters. PNNL has made some advances in automating this process to allow users to create a batch list of jobs which are prioritized and efficiently managed over a small number of processes. PNNL will provide further enhancements to this feature (and others, where necessary), to create an internal, or incorporate an external, run management system, which dispatches jobs in an efficient manner.

A number of users have expressed interest in using GridLAB-D in a "real-time" or "runtime" environment. Proposed uses are varied. This type of access can be used as a means for hardware-in-the-loop testing or inserting, modifying, or extracting information "on-the-fly" during the simulation allowing for a graphical user interface to display the data or for users to interact with the model. PNNL has made some advances in this area, creating a "server" mode that allows users to access data via XML and HTML interfaces. PNNL will expand this capability to support new features at user request.

During creation of the OMF, it is expected that additional new models (called objects) within the GridLAB-D environment will also be needed. For example, NRECA/CRN has requested a more advanced and flexible wind turbine model for distributed generation applications and a battery control device. Within the flexibility of project constraints, these types of requests will be taken from NRECA/CRN, prioritized, and addressed as they are able to coincide with project scope and budget. 


\subsection{Task 4 - Enhance Data Management Capabilities}

GridLAB-D simulations are detailed and complex, and can be thought of analogous to a field demonstration of new technologies, producing large amounts of highly granular data. This is especially true when looking at Monte Carlo simulations, exploration of different set points, or long periods of time. Ideally, this data production should not be accessed through text files and post-processing scripts, but rather through an adaptable database management system. PNNL will address these concerns by expanding current database structures, creating a flexible database management system.

\subsection{Task 5 - Provide Priority Bug Fixes}

NRECA/CRN will be an active and important user of version 3.0 (and beyond) of GridLABD. As a development version slated for release in summer of 2013, it is expected that this version may have a number of "bugs" which prevent NRECA/CRN from moving forward on the collaborative effort in a timely manner. PNNL will provide priority bug fix resources for NRECA/CRN, accelerating GridLAB-D fixes when they slow production of the OMF. These will be performed on a by request basis, within scope and budget of the project, and will be completed prior to "pre-release" of GridLAB-D version 3.0 in August of 2013.

\subsection{Task 6 - Assist in WindMil to GridLAB-D Translation}

Milsoft Utility Solutions' WindMil distribution analysis tool is used by more than 1,100 utilities throughout the United States, incorporating planning, analysis, and operation into a single software environment [12]. Despite its vast capabilities and resources, and its strong reputation, there are certain types of analyses that are needed by utilities that are not suited to this environment. Translation of utility models from this environment into the GridLAB-D format will enhance utility planning and analysis capabilities. The combined advantages of a powerful, user-friendly commercial product and an advanced analytic, open-source tool will create a toolbox of analysis capabilities that will allow utilities to more quickly adopt cost-effective grid modernization technologies. PNNL will work with NRECA/CRN and Milsoft to create an automated, standardized translation tool from WindMil utility models to GridLAB-D power flow models. This code will be provided to the open-source community, along with CYMDIST and SynerGEE scripts already available [13]-[15].

\subsection{Task 7 - General OMF Support}

PNNL staff have gathered a significant amount of experience developing feeder and technology models, particularly within the GridLAB-D environment. As appropriate, PNNL will provide subject matter expertise and advice to the OMF development team. 


\section{Project Timeline}

Figure 3-1 shows the projected task and project timelines, subject to changes within individual tasks, as needed, to support the delivery of an initial OMF demonstration in July 2013.

\begin{tabular}{|c|c|c|c|c|c|c|c|c|c|c|}
\hline & & Jan-13 & Feb-13 & Mar-13 & Apr-13 & May-13 & Jun-13 & Jul-13 & Aug-13 & Sep \\
\hline 1 & Load and Model & & & & & & & & & \\
\hline 1.1 & Feeder Population & & & & & & & & & \\
\hline 1.2 & Calibration & & & & & & & & & \\
\hline 2 & Performance & & & & & & & & & \\
\hline 3 & New Capabilities & & & 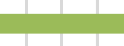 & & & & & & \\
\hline 3.1 & Wind Turbine & & & & 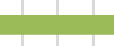 & $\vec{P}$ & & & & \\
\hline 3.2 & Battery Control & & & & & & & & & \\
\hline 4 & Data Management & & & & & & & & & \\
\hline 5 & Priority Bug Fixes & 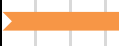 & & & & & & & & \\
\hline 6 & WindMil & 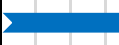 & & 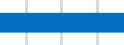 & & & & & & \\
\hline 7 & OMF Support & & & & & & & & & \\
\hline & & & & $\begin{array}{r}\text { Initialf } \\
\text { code } \\
\mathrm{Ju}\end{array}$ & $\begin{array}{l}\text { der and c } \\
\text { livered to } \\
\text { OMF rel }\end{array}$ & $\begin{array}{l}\text { libration } \\
\text { CRN for } \\
\text { se }\end{array}$ & & & $\begin{array}{r}\text { GridL } \\
\text { V3.0 wil } \\
\text { pre-re }\end{array}$ & $\begin{array}{l}\text { D } \\
\text { enter } \\
\text { ase }\end{array}$ \\
\hline
\end{tabular}

Figure 3-1: Project timeline for PNNL task completion. 


\section{References}

[1] GridLAB-D, information available online: http://www.gridlabd.org

[2] K. P. Schneider, J. C. Fuller, F. K. Tuffner, and R. Singh, "Evaluation of Conservation Voltage Reduction (CVR) on a National Level”, PNNL-19596, Pacific Northwest National Laboratory, Richland, WA, 2010.

[3] K. P. Schneider, J. C. Fuller, F. K. Tuffner, R. Singh, C. A. Bonebrake, N. Prakash Kumar, and B. Vyakaranam, "Evaluation of Smart Grid Investment Grant Project Technologies: Summary Report”, PNNL-20892, Pacific Northwest National Laboratory, Richland, WA, 2012.

[4] K. P. Schneider, J. C. Fuller, D. Chassin, "Evaluating conservation voltage reduction: An application of GridLAB-D: An open source software package," Power and Energy Society General Meeting, 2011 IEEE , vol., no., pp.1,6, 24-29, July 2011.

[5] National Rural Electric Cooperative Network / Cooperative Research Network, information available online: http://www.nreca.coop/programs/CRN/Pages/default.aspx

[6] G. Zeiss, "Open Modeling Framework for modeling the smartgrid including cost/benefit analysis", online article accessed May 2013, information available online: http://geospatial.blogs.com/geospatial/2013/02/nreca-techadvantage-open-modelingframework-for-modeling-the-electricity-grid-including-costbenefit-.html

[7] GridLAB-D, information available online: http://sourceforge.net/projects/gridlab-d/

[8] J. Fuller, N. Prakash Kumar, and C. Bonebrake, "Evaluation of Smart Grid Investment Grant Project Technologies: Demand Response", PNNL-20772, Pacific Northwest National Laboratory, Richland, Washington, 2011.

[9] K. Schneider and C. Bonebrake, "Evaluation of Smart Grid Investment Grant Project Technologies: Distribution Automation”, PNNL-20546, Pacific Northwest National Laboratory, Richland, Washington, 2011.

[10] F. Tuffner and C. Bonebrake, "Evaluation of Smart Grid Investment Grant Project Technologies: Thermal Energy Storage”, PNNL-20584, Pacific Northwest National Laboratory, Richland, Washington, 2011.

[11] R. Singh and B. Vyakaranam, "Evaluation of Smart Grid Investment Grant Project Technologies: Distributed Generation”, PNNL-20792, Pacific Northwest National Laboratory, Richland, Washington, 2011.

[12] WindMil, information available online: http://www.milsoft.com

[13] SynerGEE Electric, information available online: http://www.gl-group.com.

[14] Cymdist, information available online: http://www.cyme.com

[15] Feeder Taxonomy Scripts, information available online: https://sourceforge.net/apps/mediawiki/gridlab-d/index.php?title=Feeder_Taxonomy 


\section{Distribution}

No. of Copies

1 Dan Ton

U.S. Department of Energy

1000 Independence Avenue, SW

Washington, DC 20585
No. of Copies

$5 \quad$ Local Distribution

Pacific Northwest National Laboratory

CH Imhoff

K9-69

DA King

K2-12

RG Pratt

K1-85

SE Widergren

K1-85

1 David Pinney

NRECA

Arlington, VA 
PNNL-22489

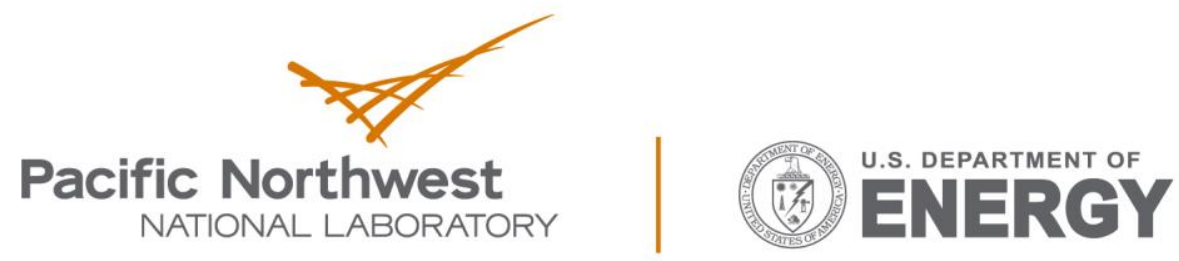

Proudly Operated by Battelle Since 1965

902 Battelle Boulevard

P.O. Box 999

Richland, WA 99352

1-888-375-PNNL (7665)

www.pnnl.gov 